\title{
Assessing the impact of tidal stream energy extraction on the Lagrangian circulation
}

\author{
by
}

Nicolas Guillou and Georges Chapalain

\author{
Applied Energy \\ 2017 \\ http://dx.doi.org/10.1016/j.apenergy.2017.06.022 \\ (C) 2017 Elsevier Ltd All rights reserved
}

Please note that this is an author-produced PDF of the draft of the manuscript submitted to Applied Energy. The definitive publisher-authenticated version is available on the publisher Web site. 


\title{
Assessing the impact of tidal stream energy extraction on the Lagrangian circulation
}

\author{
Nicolas Guillou ${ }^{\mathrm{a}, *}$, Georges Chapalain ${ }^{\mathrm{a}}$ \\ ${ }^{a}$ Laboratoire de Génie Côtier et Environnement (LGCE), Cerema/DTecEMF/ER, 155 rue Pierre Bouguer, Technopôle \\ Brest-Iroise - BP 5 - 29280 Plouzané, France
}

\begin{abstract}
Whereas numerous numerical modelling have been conducted to gain further insights about the hydrodynamic characteristics of tidal stream energy sites, the long-term transport of water particles has been routinely ignored. However, a refined evaluation of circulation pathways is fundamental to assess water-quality changes induced by tidal energy converters. The present study investigates the tide-induced Lagrangian circulation in north-western coastal waters of Brittany (France, western Europe), including numerous islands, shoals and straits with strong potential for turbine farm implementation. Particular attention is dedicated to the hydrodynamic impact of tidal stream power extraction from a series of horizontal-axis turbines. An original approach, based on the coupling of the Lagrangian barycentric method with predictions from a model with high spatial resolution, is considered to assess circulation pathways in a single synoptic view. Spatial results reveal a complex Lagrangian circulation highly controlled by bathymetry and islands geometry. The residual flow in the Fromveur Strait, separating Ushant island from Molène archipelago, displays thus a strong asymmetry, between a prominent north-eastern pathway with residual currents up to $0.45 \mathrm{~m} \mathrm{~s}^{-1}$ and a southward circulation. The positions of cyclonic and anti-cyclonic recirculations, both upstream and downstream the Strait, are furthermore precisely defined. The north eddy is found closely located to the sand bank of the Four. The extraction of tidal stream power impacts mainly the residual Lagrangian circulation along the current stream emerging from the Strait, with a tendency for surrounding eddies to get closer to the tidal stream energy site. The displacements of the south and north recirculations may thus exceed $1.5 \mathrm{~km}$ with possible implications on the evolution of surrounding seabed features.
\end{abstract}

Keywords: tidal flow asymmetry, tidal velocity, Eulerian currents, water particles, drifters, western Brittany

\section{Introduction}

The kinetic energy of tidal currents is becoming a reliable alternative solution to increase the rate of renewable and clean resources in the increasing worldwide production of electricity. Technologies for tidal hydrokinetic energy extraction, commonly based on horizontal-axis

\footnotetext{
${ }^{*}$ Corresponding author

Email addresses: nicolas.guillou@cerema.fr (Nicolas Guillou ), georges. chapalain@cerema.fr (Georges Chapalain) 
turbines [1], are thus developing very rapidly, with numerous full-scale devices deployed and tested in potential tidal stream sites. Accurate and refined assessments of ambient hydrodynamic conditions have thus been conducted to optimise design and locations of turbine-based energy converters $[2,3,4,5]$. Numerical modelling tools were most of the time retained to complement in-situ observations. Nevertheless, whereas numerous numerical studies have exhibited the hydrodynamic effects induced by tidal stream power extraction $[6,7,8,9,10]$, the long-term influence on water-mass transport has been routinely ignored in sites characterisation. Transport studies in potential tidal stream sites have furthermore primarily focused on the impacts of energy extraction on suspended sediment fluxes [11, 12], setting aside in-depth investigations of modifications of local tide-induced pathways. A preliminary numerical analysis of passive tracer pathways in a tidal stream energy site was conducted by Shapiro [13], considering a hypothetical array of turbines in the Celtic Sea, north of Cornwall (United-Kingdom). Nevertheless, simulations were restricted to a single release of floats, neglecting the influence of initial conditions on drifters transport.

Further investigations of tide-induced circulation pathways in these highly energetic environments are thus required. These aspects are particularly fundamental to gain further insights about water-quality changes induced by tidal turbines [14]. Besides the ecological interest in assessing trapping and dispersion of fish eggs, larvae, nutrients and suspended sediments [15, 16], an approach of long-term water-particles displacements may also serve more specific objectives of interest for turbines developers, like transports predictions of (1) drifters potentially harmful to tidal stream energy converters or (2) polluting substances accidentally released by devices. Depending on the marine and coastal environments considered, drifters can thus take different forms ranging from simple piece of wood, plastic wastes [17] to large sediment-laden ice cakes [18]. With sufficiently near neutral buoyancy to be transported in the water column under the high-current speed of tidal stream energy sites, these drifters may represent a potential danger to submerged turbines by damaging devices or disturbing blades rotation. Maintenance products used to prevent the development of algae and organisms on the turbine structure could furthermore affect the surrounding aquatic fauna and flora. Whereas low quantities of chemicals products or oils may be accidentally released, it would finally constitute a nuisance to the marine protected areas where high constraints are imposed on water quality.

Since the pioneering investigations of Zimmerman [19] and Cheng and Casulli [20], the long-term transport of water mass is commonly evaluated with the Lagrangian residual current, defined as the displacement of water particles over a time interval such as the tidal period. The Lagrangian description appears thus particularly suited to represent, with higher accuracy, the tide-induced transport pathways and approach the associated mixing, exchange and residence time scales of water mass. Nevertheless, as water particles may follow different trajectories depending on the released time during a tidal cycle, the associated Lagrangian residual currents are characterised by a strong dispersion and appear very difficult to define in a single and simple synoptic view. An original numerical method, entitled "Lagrangian barycentric" and based on particles tracking, has however been proposed by Salomon et al. [21] and Orbi and Salomon [22] to map the Lagrangian residual currents induced by a single monochromatic tidal component such as the principal lunar semi-diurnal tidal constituent $\mathrm{M}_{2}$. Whereas more sophisticated methods have been proposed to include velocity fields resulting from complex tidal spectrum [23], the Lagrangian barycentric approach provides, in a single synoptic cartography, a first overview of long-term transport pathways, with successful applications at the scales of the English Channel and western Brittany [21,22]. The resulting velocity fields have thus successfully been used in numerical modelling of long-term dispersion of soluble substances in these coastal environments 

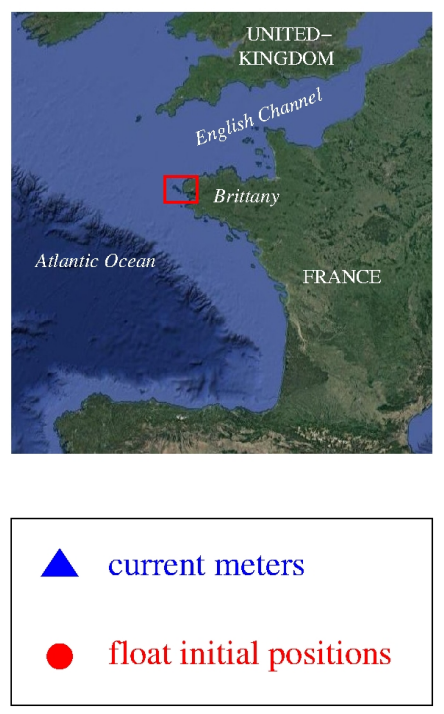
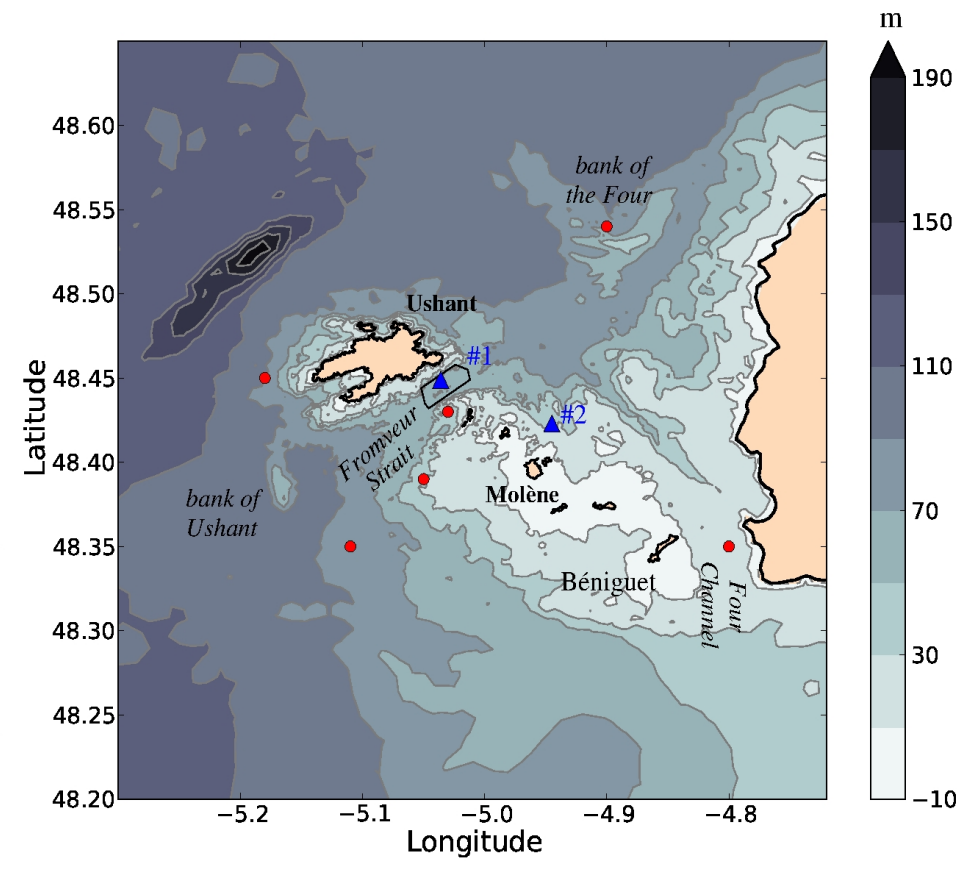

Figure 1: Bathymetry of Ushant-Molène archipelago with locations of available current meters \#1 and \#2. The red circles show the initial positions of floats for assessing long-term particles trajectories in Section 3.2.2. The black line in the Fromveur Strait delimits the area of interest identified by the French government for the implementation of turbine farm. Water depth is relative to mean sea level.

while significantly reducing the computational time $[24,25]$.

The present study analyses and exhibits, with the Lagrangian barycentric method, the effects of tidal stream energy extraction on the circulation of water particles at the local scale of a "first-generation" tidal stream site. Indeed, this type of environment, characterised by spring currents over $2.5 \mathrm{~m} \mathrm{~s}^{-1}$ and water depths in the range $25-50 \mathrm{~m} \mathrm{[26],} \mathrm{is} \mathrm{primarily} \mathrm{targeted} \mathrm{for}$ the earliest exploitation of tidal current kinetic energy and turbine farm development. The site of application is the Fromveur Strait (Fig. 1), an area off western Brittany identified, with the Alderney Race in the English Channel, as one of the largest tidal stream energy resource along the coasts of France. Numerical studies have recently been conducted in this tidal stream energy site to refine predictions of available tidal kinetic energy by quantifying the influences of bed roughness parameterisation [9] and wind-generated surface-gravity waves [5]. Nevertheless, whereas previous investigations have focused on the regional Lagrangian circulation in western Brittany $[21,27,28]$, no modelling has been specifically dedicated to capture, at higher spatial resolution (between 50 ans $100 \mathrm{~m}$ ), (1) the tide-induced circulation pathways in this Strait, and (2) modifications induced by tidal stream power extraction.

The numerical approach, adopted here, is based on a high-resolution depth-averaged tidal circulation model dedicated to the transport of floating particles released at different times of the lunar semi-diurnal tidal cycle (Section 2.1). While previous Lagrangian studies have been conducted with off-line treatments of numerical simulations [21, 27], the present investigation 
relies on a particle tracking method directly integrated to the modelling which enables a refined assessment of tide-induced trajectories. An original approach is applied to couple the Lagrangian barycentric method with predictions on an unstructured computational grid (Section 2.2). To be concordant with simulations performed by Salomon et al. [21], the investigation is conducted in idealised tidal conditions driving the numerical model by the dominant lunar semi-diurnal harmonic component $\mathrm{M}_{2}$ and the quarter-diurnal generated harmonic $\mathrm{M}_{4}$ at open sea boundaries. Indeed, this latter harmonic, generated from $\mathrm{M}_{2}$ in shelf seas environments, may also appear at open boundaries of computational domain, especially in shallow-waters areas close to landmass. As inferred in previous numerical simulations [29, 30], integrating the $\mathbf{M}_{4}$ forcings improves thus its numerical approach in the computational domain with respect to published harmonic database and in-situ observations (Section 3.1). Predictions are also assessed against available measurements of current amplitude and direction at two locations in the area of interest (Section 3.1). Besides a resulting refined synoptic view of circulation pathways of broader interest for applications in "first-generation" tidal stream sites, this study evaluates the performance of the Lagrangian barycentric method to approach long-term transport of water particles in a highly energetic environment characterised by a series of islets and rocks with complex tidal eddies circulations and significant vorticity generation (Section 3.2). Major Lagrangian circulation features are interpreted, focusing on the tidal asymmetry in the Fromveur Strait. In the perspective of turbine farm development, the effects of tidal stream power extraction on the Lagrangian residual circulation are finally evaluated with respect to the number of turbines (Section 3.3).

\section{Materials and methods}

\subsection{Numerical modelling}

Numerical simulations of the tide-induced circulation are performed, relying on the 2-dimensional horizontal model TELEMAC 2D (version v6p3) [31], modified and set up by Guillou and Thiébot [9] for the evaluation of the hydrodynamic impact of tidal stream power extraction in the Fromveur Strait. The model solves the shallow-water Barré de Saint-Venant equations of continuity and momentum, with a time step of $1 \mathrm{~s}$, on an unstructured finite-elements computational grid, covering the western extend of Brittany with a spatial resolution of $10 \mathrm{~km}$ at offshore sea boundaries to less than $50 \mathrm{~m}$ in the Fromveur Strait (Fig. 2). This unstructured grid enables a refined spatial resolution over the area of interest while restricting the computational cost of numerical simulations. The horizontal momentum eddy viscosity is computed with a depthaveraged $k-\varepsilon$ model assuming an isotropic turbulence hypothesis [31,32]. Following Guillou and Thiébot [9], major modifications, introduced here with respect to the default model version, concern the computations of (1) seabed friction at the scale of Ushant-Molène archipelago and (2) forces induced by horizontal-axis turbines on the flow at the scale of the $4.1 \mathrm{~km}^{2}$ central area in the Strait identified by the French government for the implementation of tidal stream arrays (Fig. 1). The latter type of dissipative effects corresponds to an additional bed friction sink term parametrised following the formulation proposed by Plew and Stevens [33] and devices' characteristics retained by Guillou and Thiébot [9]. In the present investigation, this corresponds to horizontal-axis tidal turbines with a blade diameter of $18.6 \mathrm{~m}$ and maximum power output of 1 MW. Further details about the mathematical expressions integrated in the numerical simulation are available in Hervouet [31] and Guillou and Thiébot [9].

Tide is considered to be the dominant hydrodynamic forcing neglecting here the influences of atmospheric pressure, wind velocity and associated surface-gravity waves whereas the Fromveur 


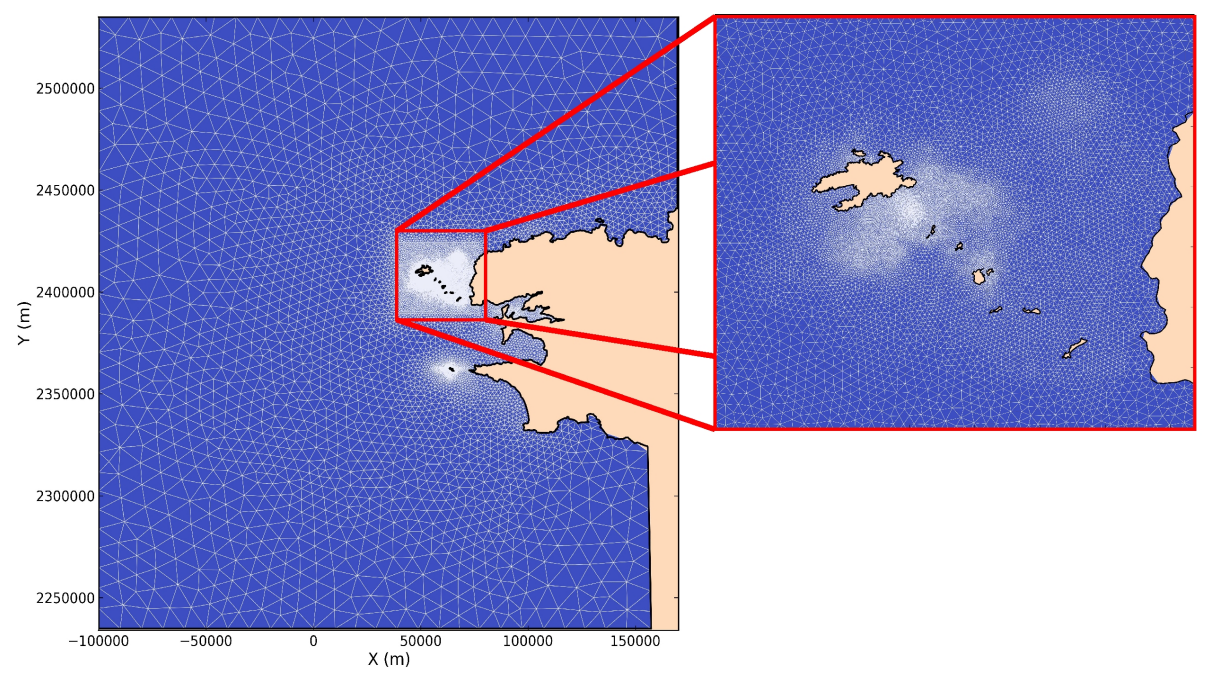

Figure 2: Computational domain with a detailed view of the unstructured grid around Ushant-Molène archipelago. Coordinates are indicated in metres according to the French system "Lambert II étendu".

Strait may be subjected to strong wave and current interactions [5, 34]. The model is thus driven, at open boundaries, by sea level variations and normal velocities derived from the dominant $\mathrm{M}_{2}$ component and the generated $\mathrm{M}_{4}$ constituent, extracted from the TPXO7-atlas 2011 database covering the area of interest with a spatial resolution of $1 / 12^{\circ}$ [35]. Trajectories of particles released at selected geographical points are computed with the transport module of TELEMAC 2D introducing a stochastic diffusion coefficient based on the turbulent eddy viscosity [36, 37]. Particles exiting through open liquid boundaries are removed, while particles crossing solid boundaries are projected along this frontier. The final outputs of the computational procedure are the recorded positions of particles, at a given time step. The effects of tidal stream power extraction on the residual Lagrangian circulation is furthermore investigated in relation to the total number of turbines placed in the tidal farm. Simulations considered thus a number of devices growing up to the extreme configuration examined by Guillou and Thiébot [9]. This corresponds to a series of fives configurations of 10, 50, 100, 150 and 207 devices. A number of 207 turbines is obtained, by adopting the configuration proposed by Thiébot et al. [11], with a density of 50 machines per $\mathrm{km}^{2}$ applied over the area identified for the implementation of tidal stream arrays in the Fromveur Strait (Fig. 1). Numerical predictions are finally compared with in-situ measurements relying on a series of statistical parameters including the mean relative difference

$$
\mathrm{DIFF}_{\mathrm{rel}}=\frac{1}{n} \sum_{i=1}^{i=n}\left(y_{i}-x_{i}\right),
$$

the index of agreement [38]

$$
\mathrm{RE}=1-\frac{\sum_{i=1}^{i=n}\left(x_{i}-y_{i}\right)^{2}}{\sum_{i=1}^{i=n}\left(\left|x_{i}-\bar{x}\right|+\left|y_{i}-\bar{x}\right|\right)^{2}}
$$


and the Pearson's correlation coefficient

$$
\mathrm{R}=\frac{\sum_{i=1}^{i=n}\left(x_{i}-\bar{x}\right)\left(y_{i}-\bar{y}\right)}{\left(\sum_{i=1}^{i=n}\left(x_{i}-\bar{x}\right)^{2} \sum_{i=1}^{i=n}\left(y_{i}-\bar{y}\right)^{2}\right)^{1 / 2}}
$$

where $n$ is the number of data in the discretised series considered, $\left(x_{i}\right)$ and $\left(y_{i}\right)$ represent the two sets of observed and simulated data, and $\bar{x}$ and $\bar{y}$ are the mean values of observed and modelled data, respectively. Positive values of $\mathrm{DIFF}_{\text {rel }}$ account for a mean overestimation of observations, whereas negative values indicate a mean underestimation. The index $R E$ which varies between 0 and 1 equals to unity for perfect agreement.

\subsection{Lagrangian barycentric method}

As the Lagrangian barycentric method has been described in details by Salomon et al. [21], Salomon and Breton [39] and Orbi and Salomon [22], this section resumes its main steps in relation to the model's implementation in the studied area. The first stage consists in computing the trajectories of floating particles released at hourly interval during a $\mathrm{M}_{2}$ tidal cycle. The initial particles positions, which have to be spread over the area of interest, are the 14,026 nodes of the unstructured computational grid surrounding Ushant-Molène archipelago [9]. Over this area, a refined coverage of floats is thus considered to compute the tide-induced trajectories and the associated Lagrangian residual current field. The residual Lagrangian vector is defined as the displacement of water particles divided by the tidal period [19, 20]. Nevertheless, for a given initial location, particles, released at different times of a tidal cycle, follow different trajectories, which results in a strong dispersion of associated residual Lagrangian vectors [22, 39]. In particular, the computed vector field can not be assigned to the initial positions of water particles characterised by a beam of Lagrangian velocities. In order to reduce the dispersion of the vector field, the second stage of the method allocates the computed residual currents at the barycentre of particles trajectories, considered to be more representative of particles displacements. This results in a field of 182,338 vectors $(=13 \times 14,026)$ covering the Ushant-Molène archipelago, at high spatial resolution, and with small discordances between vectors gathered in the same area [22]. The computed velocity field can be interpolated to obtain a gridded distribution of the Lagrangian currents. The nondivergence of the velocity field is finally evaluated. The major outcome of the barycentric method is a single Lagrangian residual velocity field which can be exploited to depict the tide-induced transport of particles in the area of interest. However, further investigation will be conducted in Sections 3.2.1 and 3.2.2 to evaluate the consistency of this residual field.

\section{Results and discussion}

\subsection{Evaluation of model predictions}

In the present investigation, the attention is dedicated to the Lagrangian transport induced by the dominant $\mathrm{M}_{2}$ tide at the scale of Ushant-Molène archipelago. Focus is thus put here on model's performances in approaching the lunar semi-diurnal harmonic component and its derivative $\mathrm{M}_{4}$ in western Brittany. Predicted amplitudes and phases of harmonic components are obtained by simple Fourier analyses of simulated tidal free-surface elevations at each nodes of the computational grid. The resulting spatial distributions are in general agreement with data derived from the Finite Element Solution tidal model [40] with maximum differences in the range 
of $7 \%$ for the amplitude and $10^{\circ}$ for the phase of the principal lunar semi-diurnal harmonic component. It appears also consistent with maps published, at the scale of the European shelf seas, by Sinha and Pingree [41], or more recently by Pineau-Guillou [42]. A refined estimation of tidal components is finally performed by comparing predictions with tidal-gauge observations at four locations in western Brittany: offshore $\left(\mathrm{S} 1, \lambda=6.033^{\circ} \mathrm{W}, \phi=47.383^{\circ} \mathrm{N}\right)$, near the isle of Ushant $\left(\mathrm{S} 2, \lambda=5.100^{\circ} \mathrm{W}, \phi=48.450^{\circ} \mathrm{N}\right)$, and in the harbors of Brest $\left(\mathrm{S} 3, \lambda=4.495^{\circ} \mathrm{W}\right.$, $\left.\phi=48.383^{\circ} \mathrm{N}\right)$ and Roscoff $\left(\mathrm{S} 4, \lambda=3.967^{\circ} \mathrm{W}, \phi=48.717^{\circ} \mathrm{N}\right)$ (Table 1). Predicted values reproduce fairly well the observed amplitudes and phases of harmonic components. Predictions approach, in particular, the increase of $\mathrm{M}_{2}$ amplitudes from the southern boundary till the north-eastern part of western Brittany with differences restricted to $0.02 \mathrm{~m}$ ( $1 \%$ of the observed amplitude). The greater disparities for predictions of $\mathrm{M}_{4}$ component at point $\mathrm{S} 4$ are consistent with results obtained by Sinha and Pingree [41], and may be attributed to the degraded spatial resolution of the regional model in this area characterised by offshore islands and shoals. Nevertheless, these comparisons confirm model's performances in assessing tide-induced vertical variations in western Brittany and Ushant-Molène archipelago.

The evaluation of model predictions is completed by a comparison of numerical results with in-situ observations of current amplitude and direction acquired, with a $600 \mathrm{kHz}$ RDI ADCP (Acoustic Doppler Current Profiler) by the French Navy SHOM ("Service Hydrographique et Océanographique de la Marine"), from 19 March to 2 April 1993 at point $\# 1\left(\lambda=5.036^{\circ} \mathrm{W}\right.$, $\left.\phi=48.449^{\circ} \mathrm{N}\right)$ and from 14 May to 11 June 1993 at point $\# 2\left(\lambda=4.945^{\circ} \mathrm{W}, \phi=48.423^{\circ} \mathrm{N}\right)$ (Figs. 1, 3 and 4). The comparison is performed $10 \mathrm{~m}$ above the bed as this corresponds to the operating height of horizontal-axis turbines in the tidal Strait [5]. Predicted values, at $10 \mathrm{~m}$ above the bed, are obtained from computed depth-averaged velocities assuming a vertical logarithmic profile in the water column. Whereas predictions have already been assessed against these measurements by Guillou and Thiébot [9], these comparisons are briefly recalled here as modifications have been brought to the tidal circulation model, in particular the database considered to drive simulations (Section 2.1). However, in the present investigation, slight differences are obtained with the initial predictions. Simulations reproduce thus fairly well the evolution of current amplitude in the Fromveur Strait (point \#1) with a Pearson's correlation coefficient of 0.96 (Fig. 3 and Table 2). Whereas increased differences are obtained in the northern part of Molène archipelago (point \#2), seemingly associated with the approach of the complex hydrodynamic recirculations in the vicinity of islands, predictions approach the pronounced observed asymmetry of tidal currents (Fig. 4). At this measurement point, the index of agreement for predictions of current amplitude is thus estimated at 0.79 . In both cases, abrupt changes between south-west and north-east directions are also simulated.

Table 1: Observed and predicted amplitudes A (in $\mathrm{m}$ ) and phases $\mathrm{g}$ (in degrees relative to Greenwich) for $\mathbf{M}_{2}$ and $\mathbf{M}_{4}$ harmonic constituents at four measurement stations in western Brittany. Observations are derived from the compilation established by Sinha and Pingree [41] and Pouvreau [43]. Predicted values are only extracted in cases of available measurements.

\begin{tabular}{|c|c|c|c|c|c|c|c|c|}
\hline \multirow{3}{*}{$\begin{array}{l}\text { Station } \\
\text { number }\end{array}$} & \multicolumn{4}{|c|}{$\mathrm{M}_{2}$} & \multicolumn{4}{|c|}{$\mathrm{M}_{4}$} \\
\hline & \multicolumn{2}{|c|}{ Observed } & \multicolumn{2}{|c|}{ Modelled } & \multicolumn{2}{|c|}{ Observed } & \multicolumn{2}{|c|}{ Modelled } \\
\hline & A & $\mathrm{g}$ & A & $\mathrm{g}$ & A & $\mathrm{g}$ & A & $\mathrm{g}$ \\
\hline S1 (offshore) & 1.36 & 99.7 & 1.35 & 90.9 & $1.2 \times 10^{-2}$ & 296.5 & $1.2 \times 10^{-2}$ & 290.3 \\
\hline S2 (Ushant) & 2.07 & 111.0 & 2.09 & 99.9 & - & - & - & - \\
\hline S3 (Brest) & 2.05 & - & 2.06 & - & $5.4 \times 10^{-2}$ & - & $6.8 \times 10^{-2}$ & - \\
\hline S4 (Roscoff) & 2.70 & 142.8 & 2.69 & 133.1 & $5.4 \times 10^{-2}$ & 143.4 & $9.1 \times 10^{-2}$ & 120.0 \\
\hline
\end{tabular}



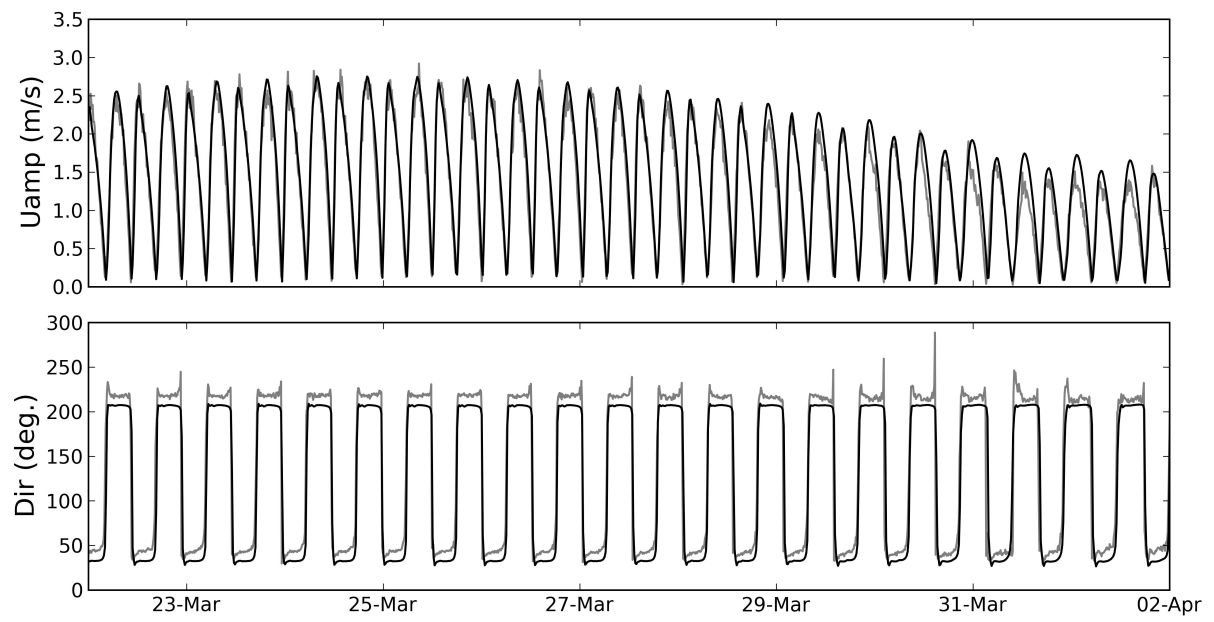

Figure 3: Measured (gray line) and computed (black line) time series of the amplitude and direction (anticlockwise convention from the East) of the current $10 \mathrm{~m}$ above the bed at point \#1 in March-April 1993.

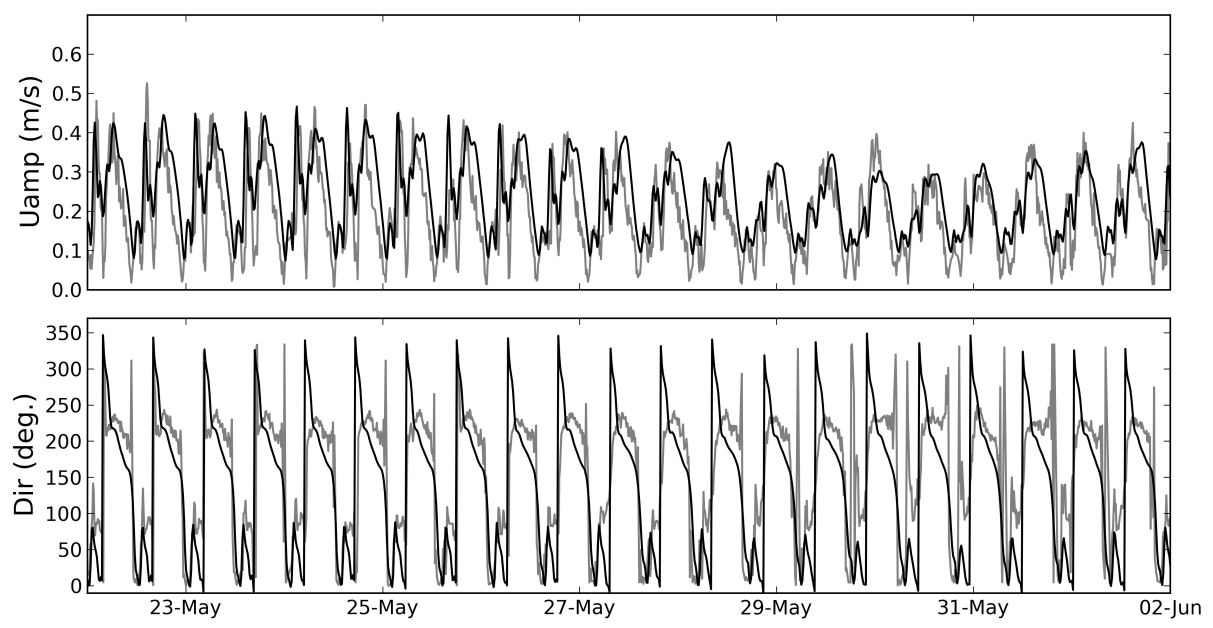

Figure 4: Measured (gray line) and computed (black line) time series of the amplitude and direction (anticlockwise convention from the East) of the current $10 \mathrm{~m}$ above the bed at point \#2 in May-June 1993.

Table 2: Statistical parameters associated with predictions of amplitude $\mathrm{U}_{\mathrm{amp}}$ and direction Dir of currents $10 \mathrm{~m}$ above the bed at points \#1 and \#2.

\begin{tabular}{|c|c|c|c|c|c|c|}
\hline \multirow{2}{*}{$\begin{array}{l}\text { Measurement } \\
\text { points }\end{array}$} & \multicolumn{3}{|c|}{ Uamp } & \multicolumn{3}{|c|}{ Dir } \\
\hline & DIFF $_{\text {rel }}$ & RE & $\mathrm{R}$ & DIFF $_{\text {rel }}$ & $\mathrm{RE}$ & $\mathrm{R}$ \\
\hline \#1 & $0.06 \mathrm{~m} \mathrm{~s}^{-1}$ & 0.98 & 0.96 & $-9.5^{\circ}$ & 0.98 & 0.96 \\
\hline \#2 & $0.05 \mathrm{~m} \mathrm{~s}^{-1}$ & 0.79 & 0.72 & $-14.0^{\circ}$ & 0.88 & 0.82 \\
\hline
\end{tabular}




\subsection{Lagrangian pathways without turbines}

\subsubsection{Comparison with regional investigations}

Prior to the investigation of tide-induced circulation pathways, a brief description of predicted tidal currents is conducted at the scale of Ushant-Molène archipelago. The objective is to provide further information about the driving hydrodynamic conditions of water-particles transport in the region of interest. Predictions exhibit a central acceleration area in the Fromveur Strait with depth-averaged currents exceeding $3.0 \mathrm{~m} \mathrm{~s}^{-1}$ at times of flood and ebb peaks of a $\mathrm{M}_{2}$ tidal cycle (Fig. 5). As previously exhibited by in-situ observations at point \#1 (Fig. 3), tidal currents are furthermore oriented along the direction of the Strait. Secondary areas with high stream energy potential are finally identified (1) between islands and shoals of Molène archipelago and (2) in the western part of Ushant island. As inferred from observations [44], this latter region, characterised by water depths over $30 \mathrm{~m}$, may present an interest for the exploitation of tidal kinetic energy complementing the resource of the Fromveur Strait.

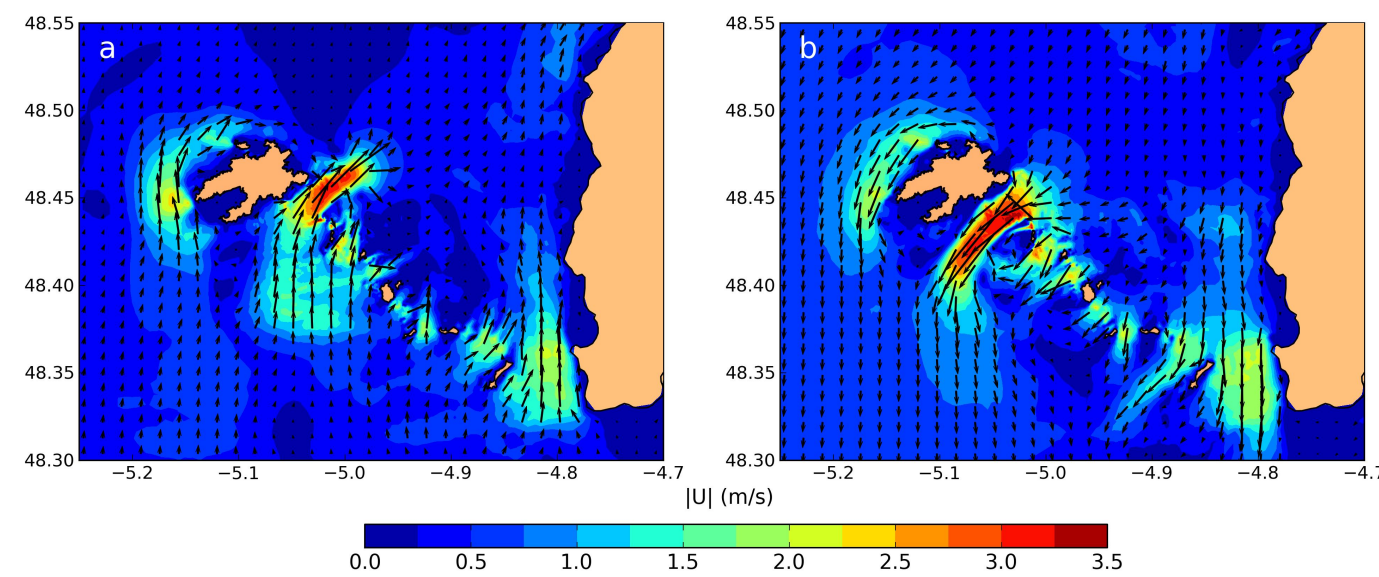

Figure 5: Depth-averaged currents without tidal stream array at times of (a) flood and (b) ebb peaks of a $\mathrm{M}_{2}$ tidal cycle in the Fromveur Strait.

At the scale of Ushant-Molène archipelago, predicted tide-induced Lagrangian residual currents (Fig. 6) appear consistent with streamlines computed, in western Brittany, by Salomon et al. [21], relying on the barycentric method. The Lagrangian circulation is thus characterised by a prominent northward pathway, appearing offshore by mean water depths of $100 \mathrm{~m}$, which deflects towards the east around Ushant island and connects to the significant circulation emerging from the Fromveur Strait, with residual currents up to $0.45 \mathrm{~m} \mathrm{~s}^{-1}$. This offshore residual circulation has also been identified by Muller et al. [27, 28] by comparing predicted streamlines with long-term trajectories of real subsurface drifters released during summers 2005 and 2007, off western Brittany. Confirming previous investigations, the present numerical modelling identifies furthermore, in the north-east of Ushant island, a prominent tide-induced cyclonic eddy, of around $8 \mathrm{~km}$ in diameter, bordering the western side of the regional Lagrangian pathway flowing towards the English Channel. However, the definite position of this residual recirculation differs between conducted analyses. Whereas Salomon et al. [21] located, for similar idealised tidal forcings, this Lagrangian structure in the north of Ushant island, Muller et al. [27, 28] positioned it further west from High-Frequency Radar (HFR) observations of the surface circulation in calm 


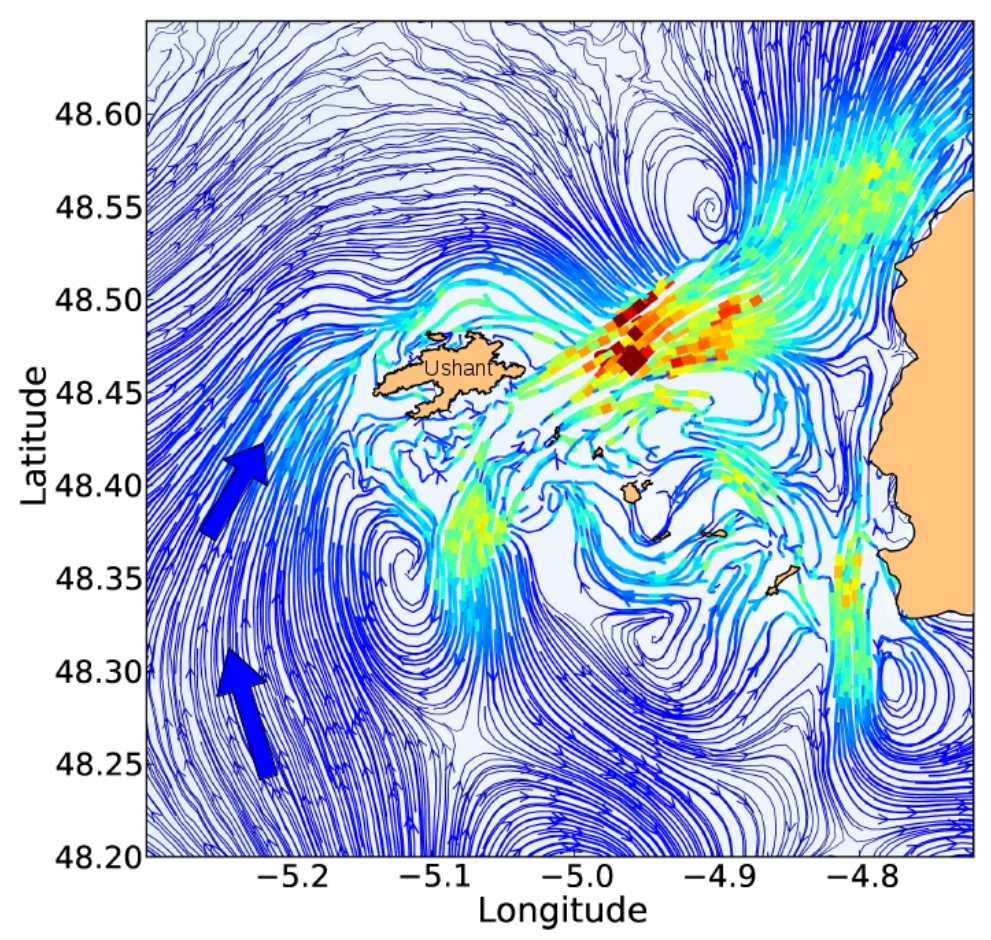

\section{Ulag $(\mathrm{m} / \mathrm{s})$}

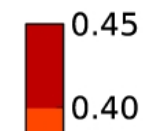

Figure 6: Streamlines from tidal residual Lagrangian currents without turbines in the Fromveur Strait. The regional northward pathway is outlined with blue arrows.

weather conditions. While effects of wind, waves and density-driven currents may account for differences between numerical predictions and surface observations, the various computed positions of the residual eddy may, more specifically, arise from the spatial resolutions of analysed data. Indeed, whereas previous studies were conducted at finer spatial resolutions of around $670 \mathrm{~m}$ for predictions and $1.5 \mathrm{~km}$ for HF observations [27], the present numerical modelling is based on high spatial resolutions reaching $50 \mathrm{~m}$ in the Fromveur Strait. Such refined approach of the tide-induced circulation in Ushant-Molène archipelago is confirmed here by the location of the predicted Lagrangian residual recirculation in close correlation with the position of the sand bank of the Four (Figs. 1 and 6). The residual cyclonic eddy is thus centered at the edge of the corner formed by the bank and extends to the southern and eastern limits of this seabed structure. As previously inferred by Neill and Scourse [45] and Guillou and Chapalain [46] near coastal irregularities, possible relationships may exist between this large sandbank and the tide-induced Lagrangian circulation. Further investigations show that this Lagrangian residual structure still exists without the sandbank, for numerical simulations removing this seabed feature from the bathymetry. Indeed, it seems that this cyclonic eddy is more likely associated with the recirculation appearing on the western edge of the flow emerging from the Fromveur Strait, as exhibited by the evolution of the vorticity of depth-averaged tidal currents at two moments during the flood period (Fig. 7). This confirms previous investigations performed by Lin et al. [47] about the generation of tide-induced eddies in an island-headland system. This may furthermore explain why 
a refined spatial resolution of the circulation in the Strait is required to capture the location of this residual eddy. Secondary residual recirculations are furthermore identified in the south of Ushant-Molène archipelago bordering Lagrangian pathways emerging from the Fromveur Strait or the Four Channel. Nevertheless, the correlation with surroundings seabed structure is more difficult to establish although the sand bank of Ushant is located in the vicinity of one residual structure (Figs. 1 and 6).

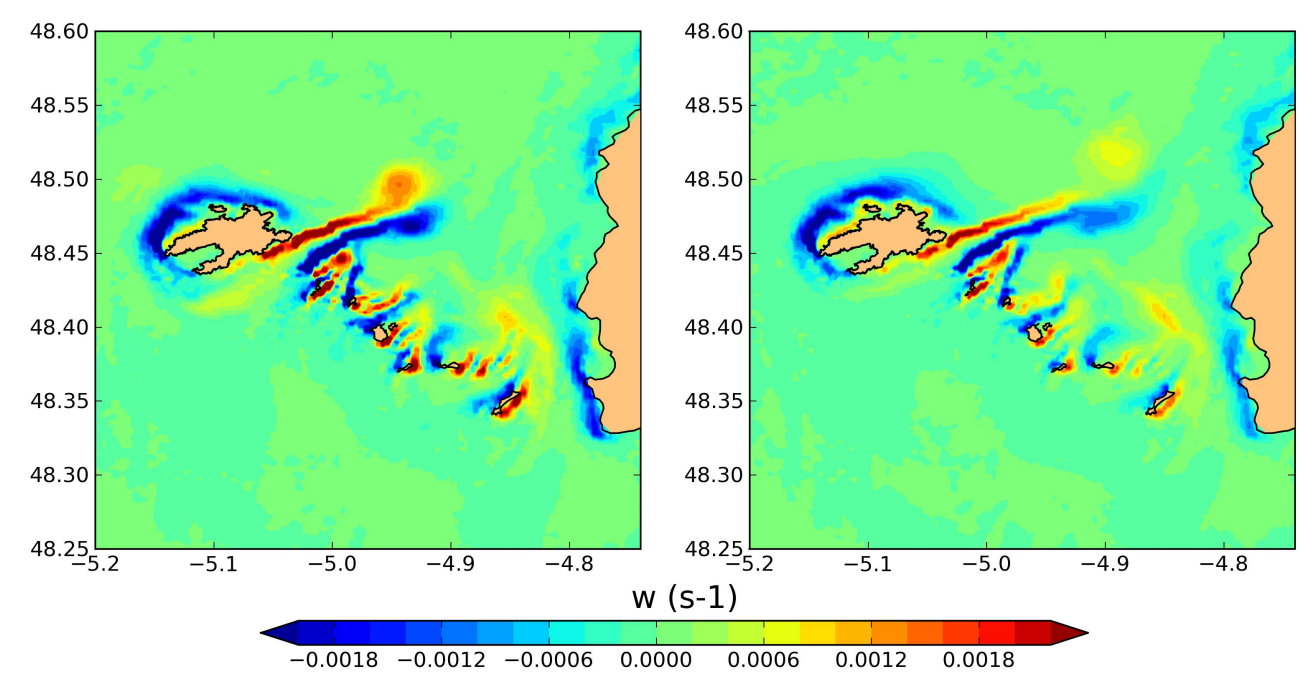

Figure 7: Vorticity of depth-averaged tidal currents at two moments during the flood period in the Fromveur Strait.

\subsubsection{Particles trajectories}

In order to further assess the consistency of the barycentric method with respect to numerical predictions, the investigation is completed by the analysis of the trajectories of floats released every two hours during a $\mathrm{M}_{2}$ tidal cycle. The objective is here to exhibit the variability of particles trajectories with respect to the initial time of release and confirm the major features of computed streamlines from tidal residual Lagrangian currents. The initial particles positions are selected at six specific locations of the residual Lagrangian circulation (Fig. 1): in the central and southern parts of the Fromveur Strait, over the bank of the Four, in the Four Channel and off the isle of Ushant. Particles positions (Fig. 8) are displayed every 12 hours to facilitate the interpretation of trajectories with respect to the computed Lagrangian current field. Depending on the initial release period, different particles trajectories are naturally obtained. Floats released in the southern part of the Strait may thus (1) directly follow the prominent north-eastern tide-induced circulation of the Fromveur Strait, (2) get around the western side of Ushant island to connect to this prominent circulation in the northern part of Molène archipelago or (3) be evacuated with southwestern currents towards the southern boundary of the area of interest. However, these various trajectories appear in the Lagrangian residual streamlines computed with the barycentric method (Fig. 6). Floats trajectories confirm, in particular, the prominent north-eastern Lagrangian pathway emerging from the Fromveur Strait. Particles released in the vicinity of the Strait remain in averaged less than three days in the area of interest before being evacuated in the northern Brittany and the English Channel. Residual eddies identified on northern and southern sides of the 
Fromveur Strait are finally revealed on particles trajectories. The cyclonic recirculation above the bank of the Four is thus exhibited on particles trajectories from an initial release in the Four Channel (Fig. 8-c).

\subsubsection{Residual Eulerian currents and tidal asymmetry}

Besides the identification of these residual eddies, predicted streamlines exhibit a strong asymmetry of the tide-induced Lagrangian circulation in the Fromveur Strait, between (1) a dominant north-eastern pathway and (2) a southward circulation. Such spatial distribution is partly associated with the asymmetry of tidal currents in the Strait, characterised by a northeastern flood-dominated sector and a southward ebb-dominated region [9], as confirmed by the spatial distribution of predicted residual Eulerian depth-averaged currents during a $\mathrm{M}_{2}$ tidal cycle (Fig. 9). Indeed, these residual Eulerian currents represent the average of velocities vectors over a tidal cycle, exhibiting differences in magnitude and direction between flood and ebb periods. Asymmetry of tidal currents may arise from the phase relationship between the principal lunar semi-diurnal constituent $\mathrm{M}_{2}$ and its first quarter-diurnal harmonic $\mathrm{M}_{4}$, expressed as $\beta=2 \phi_{\mathbf{M}_{2}}-\phi_{\mathbf{M}_{4}}$ with $\phi_{\mathbf{M}_{2}}$ and $\phi_{\mathbf{M}_{4}}$ the phases (in degrees) of $\mathbf{M}_{2}$ and $\mathbf{M}_{4}$ tidal current constituents [48, 49]. Maximum asymmetry of tidal currents is thus obtained for $\beta=0^{\circ}$ and $\beta=180^{\circ}$ whereas symmetry is reached for $\beta=90^{\circ}$ and $\beta=270^{\circ}$. The relationship between the phase lag of tidal current constituents and its asymmetry has been ascertained, by Neill et al. [2], in the tidal stream energy site of Orkney (northern Scotland) relying on numerical predic-
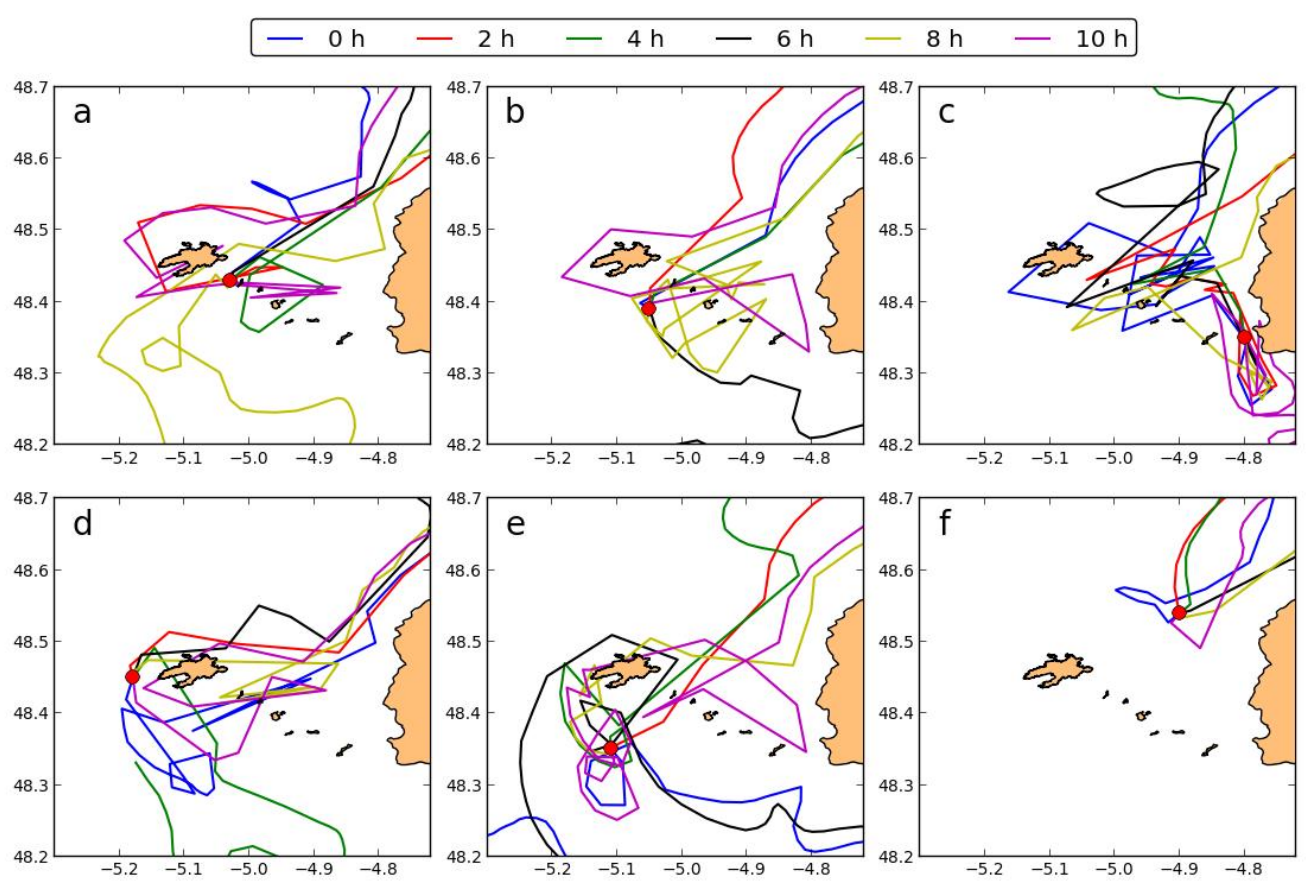

Figure 8: Long-term trajectories resulting from the larging of floats released every two hours during a $\mathbf{M}_{2}$ tidal cycle. The legend indicates the release time from the low tide in the Fromveur Strait. The initial positions of floats are displayed with red circles. Particles positions are displayed every 12 hours. 


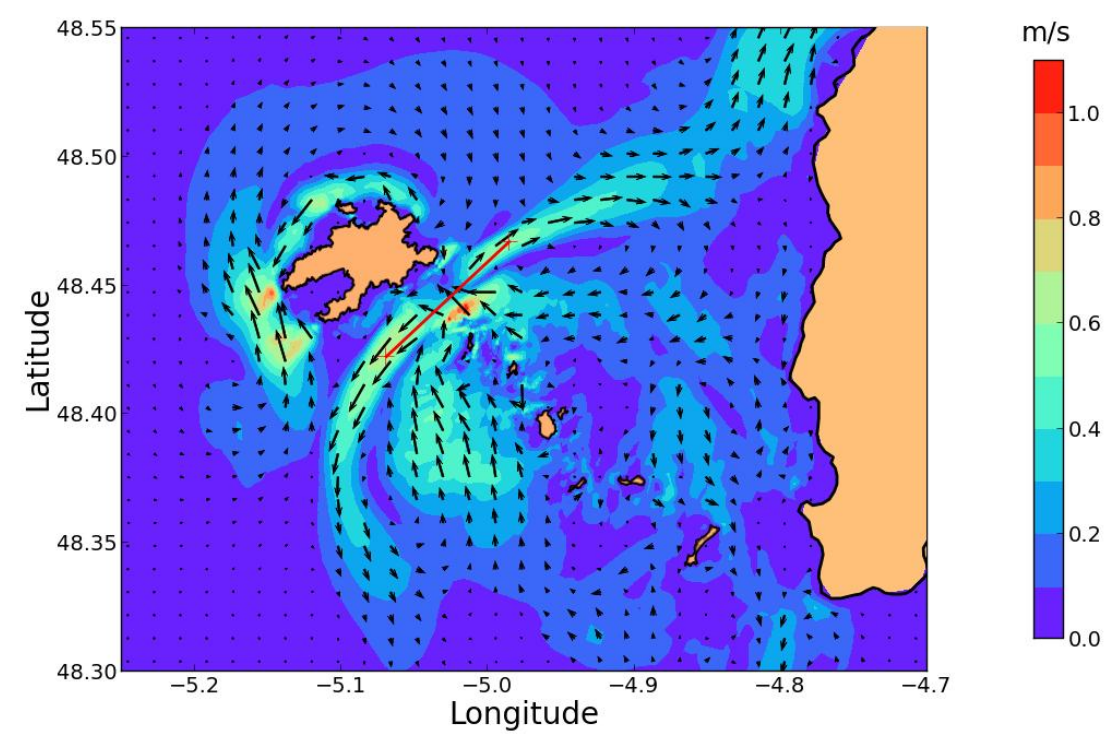

Figure 9: Predicted residual Eulerian depth-averaged currents, resulting from $\mathrm{M}_{2}$ and $\mathrm{M}_{4}$ tidal forcings, at the scale of Ushant-Molène archipelago during a $\mathbf{M}_{2}$ tidal cycle. The asymmetry of tidal currents is more specifically analysed, in Fig. 10, over the red line in the Fromveur Strait.

tions. More recently, similar investigations have been conducted by Thiébaut and Sentchev [50], in the Fromveur Strait, from observed HFR surface velocity time series. The present numerical investigation corroborates these effects by performing a harmonic analysis of predicted tidal currents along a line crossing the Strait (Figs. 9 and 10). The amplitude of Eulerian tidal currents appears thus closely related to the phase lag between $\mathbf{M}_{2}$ and $\mathbf{M}_{4}$ harmonic components. This is, in particular, exhibited by the location of the symmetry area $\left(U_{\text {res,proj }}=0\right)$ which nearly matches the area where $\beta=90^{\circ}$.

Following investigations initially conducted by Longuet-Higgins [51], the comparison of Figs. 6 and 9 exhibits furthermore the limitation of the Eulerian point of view to approach the long-term transport of water particles. Differences between the two approaches are particularly noticeable in the northern entrance of the Fromveur Strait, the southern part of Molène archipelago and the western side of Ushant island confirming a part of regional investigations conducted by Muller et al. [27] at the scale of western Brittany.

\subsection{Effects of tidal stream power extraction}

\subsubsection{Power produced and available}

Fig. 11 presents the evolution of the mean available tidal stream power during a $\mathrm{M}_{2}$ tidal cycle with respect to the number of turbines. The extraction of tidal stream power results in a reduction of tidal currents inside the array, and both upstream and downstream the turbines farm. However, acceleration areas are identified on the side of the flow emerging from the Fromveur Strait in relation to deviation of tidal currents [9]. Tidal currents appear thus to deviate up upstream and downstream the Strait exhibiting increase of available power on areas adjacent to the main flow. Whereas this reduction appears to follow a linear trend with a mean available power, during 


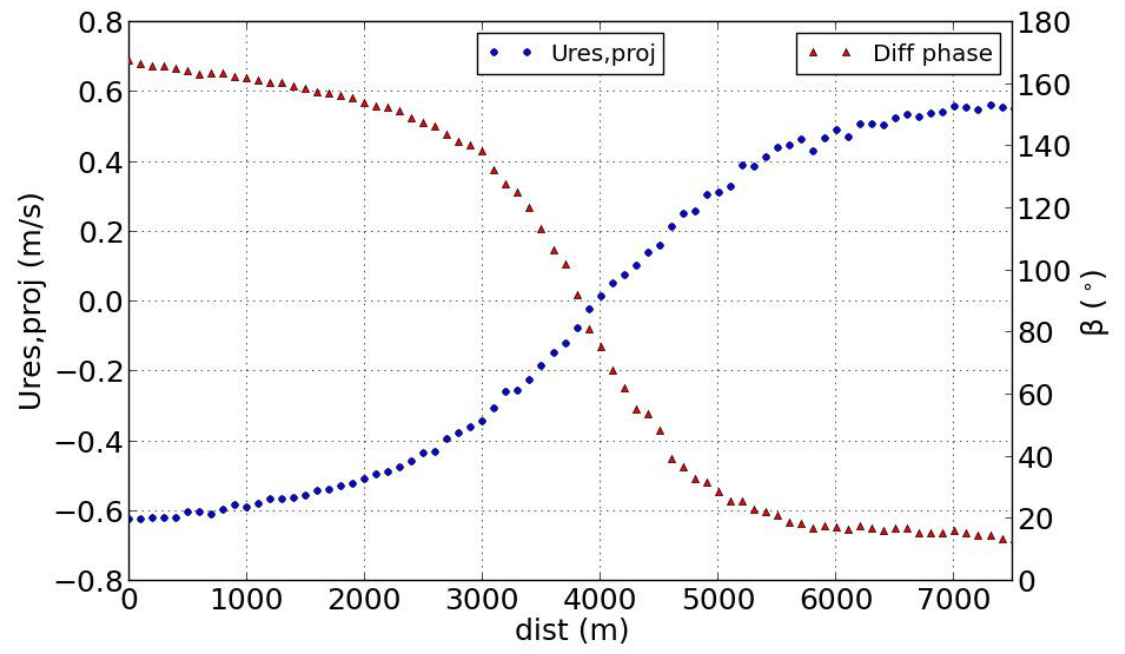

Figure 10: Evolution, along the red line crossing the Fromveur Strait (Fig. 9), of (blue circles) projected residual Eulerian currents $\mathrm{U}_{\text {res,proj }}$ and (red triangles) phase lag $\beta=2 \phi_{\mathrm{M}_{2}}-\phi_{\mathrm{M}_{4}}$ of projected tidal current constituents. The distance is indicated in metres with respect to the south-western limit of the line.
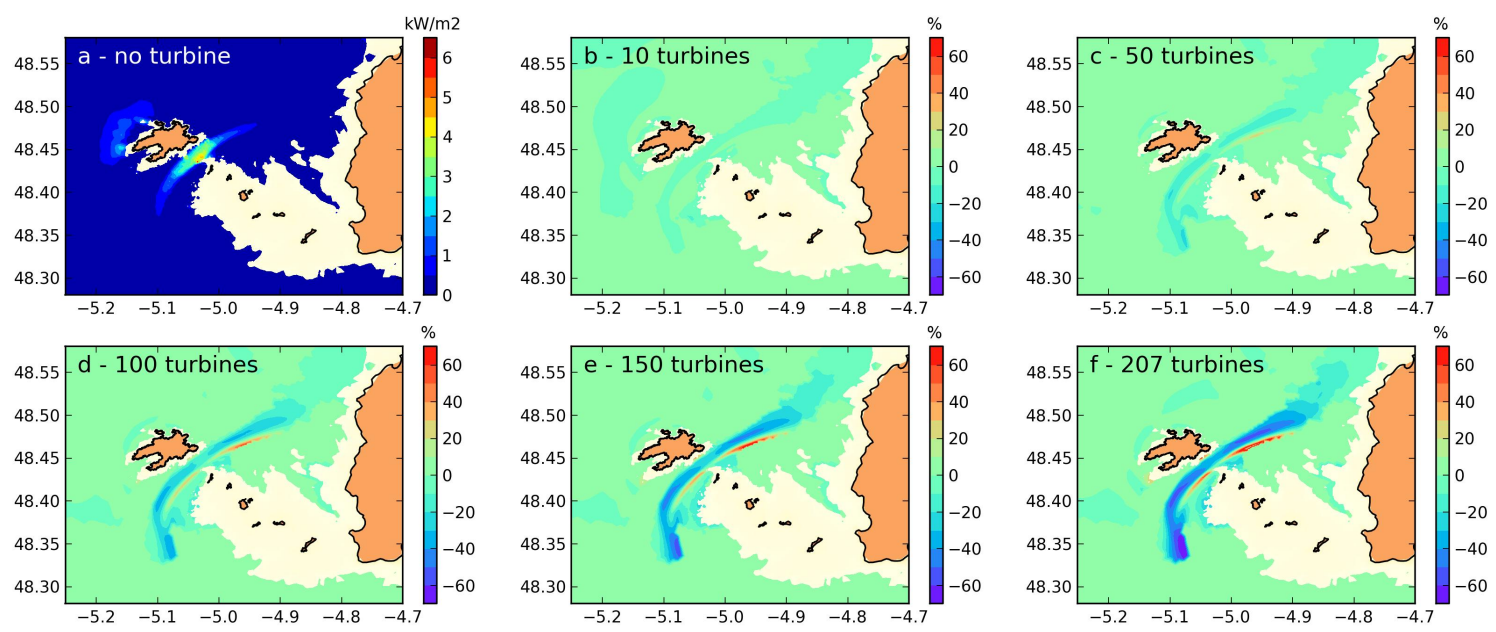

Figure 11: (a) Mean tidal stream power predicted without turbines, $10 \mathrm{~m}$ above the bed, during a $\mathrm{M}_{2}$ tidal cycle. Relative differences, expressed as percentages of values without turbines, in predictions of mean tidal stream powers for different numbers of devices in the tidal farm.

a $\mathrm{M}_{2}$ tidal cycle in the Fromveur Strait, decreasing by $8 \%$ for 50 devices and by more than $30 \%$ in the extreme configuration (207 devices), differences are exhibited by focusing on the mean power produced per device. Indeed, the operated tidal farms with 150 and 207 devices increase significantly the period of time when velocities are below the design speeds of turbines, resulting in a drop in power produced per energy converter. The mean power produced per 


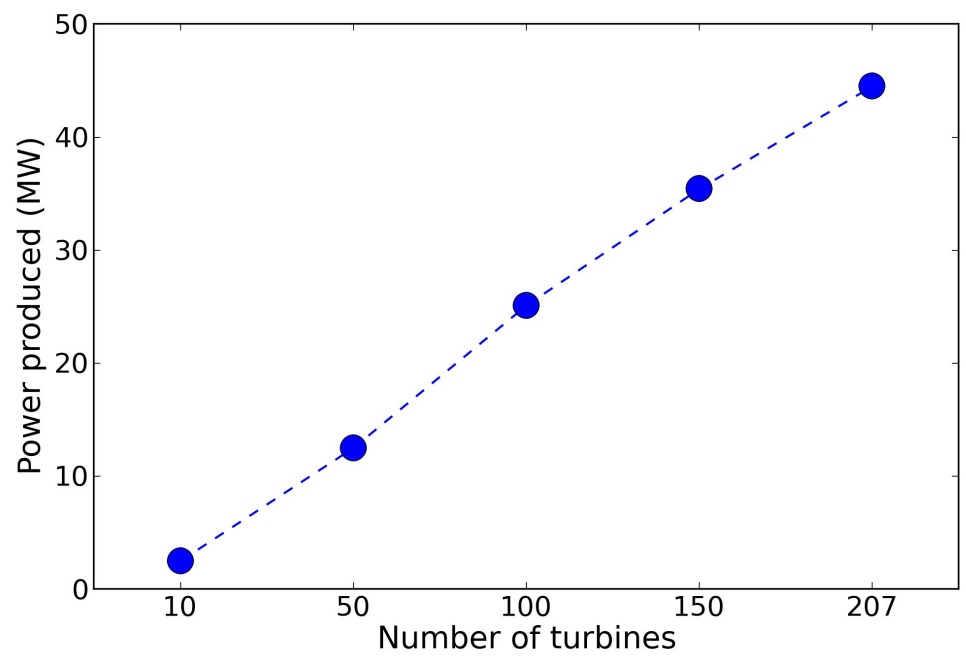

Figure 12: Mean power produced over a $\mathrm{M}_{2}$ tidal cycle for the different configurations of the tidal farm considered in the Fromveur Strait.

device, during a $\mathrm{M}_{2}$ tidal cycle, remains thus nearly stable, equals to $0.25 \mathrm{MW}$, for the first three farm configurations (10, 50 and 100 turbines) whereas it decreases to 0.24 and $0.21 \mathrm{MW}$ for 150 and 207 turbines, respectively (Fig. 12). This evolution is consistent with previous investigations conducted by Plew and Stevens [33] in the Tory Channel (New Zealand) or Shapiro [13] in the Celtic Sea.

Confirming regional numerical investigations conducted by Ahmadian et al. [52], Neill et al. [53] or Guillou and Thiébot [9], the effects of tidal stream power extraction extend furthermore at a distance of several kilometres from the array (Fig. 11). For the extreme tidal farm configuration, a reduction by more than $40 \%$ of the mean available power is thus obtained at more than $10 \mathrm{~km}$ from the site of energy extraction, this area being more extended in the south-eastern part of the Fromveur Strait. These far-field modifications of tide-induced hydrodynamic conditions suggest regional effects on the Lagrangian circulation.

\subsubsection{Lagrangian pathways}

Tidal stream power extraction impacts mainly (1) the amplitude and direction of the Lagrangian circulation emerging from the Fromveur Strait and (2) the locations of surrounding residual eddies. These hydrodynamic effects, particularly noticeable for the extreme configuration with a total number of 207 turbines (Figs. 13 and 14), are, more specifically, correlated with differences induced on tidal velocities exhibited in the previous section. Following tidal currents deviation, the southward Lagrangian pathway is thus found to deviate towards the west modifying the position of the anti-cyclonic eddy identified in the vicinity of the bank of Ushant. Changes induced on the prominent north-eastern pathway emerging from the Fromveur Strait appear furthermore to switch towards the south-west the position of the tide-induced cyclonic eddy, identified in the north-east of Ushant island (Section 3.2.1). In the extreme configuration, the locations of the south and north recirculations are modified by 3 and $1.7 \mathrm{~km}$, respectively (Figs. 14 and 15). As exhibited in previous sections, such induced modifications may have pos- 

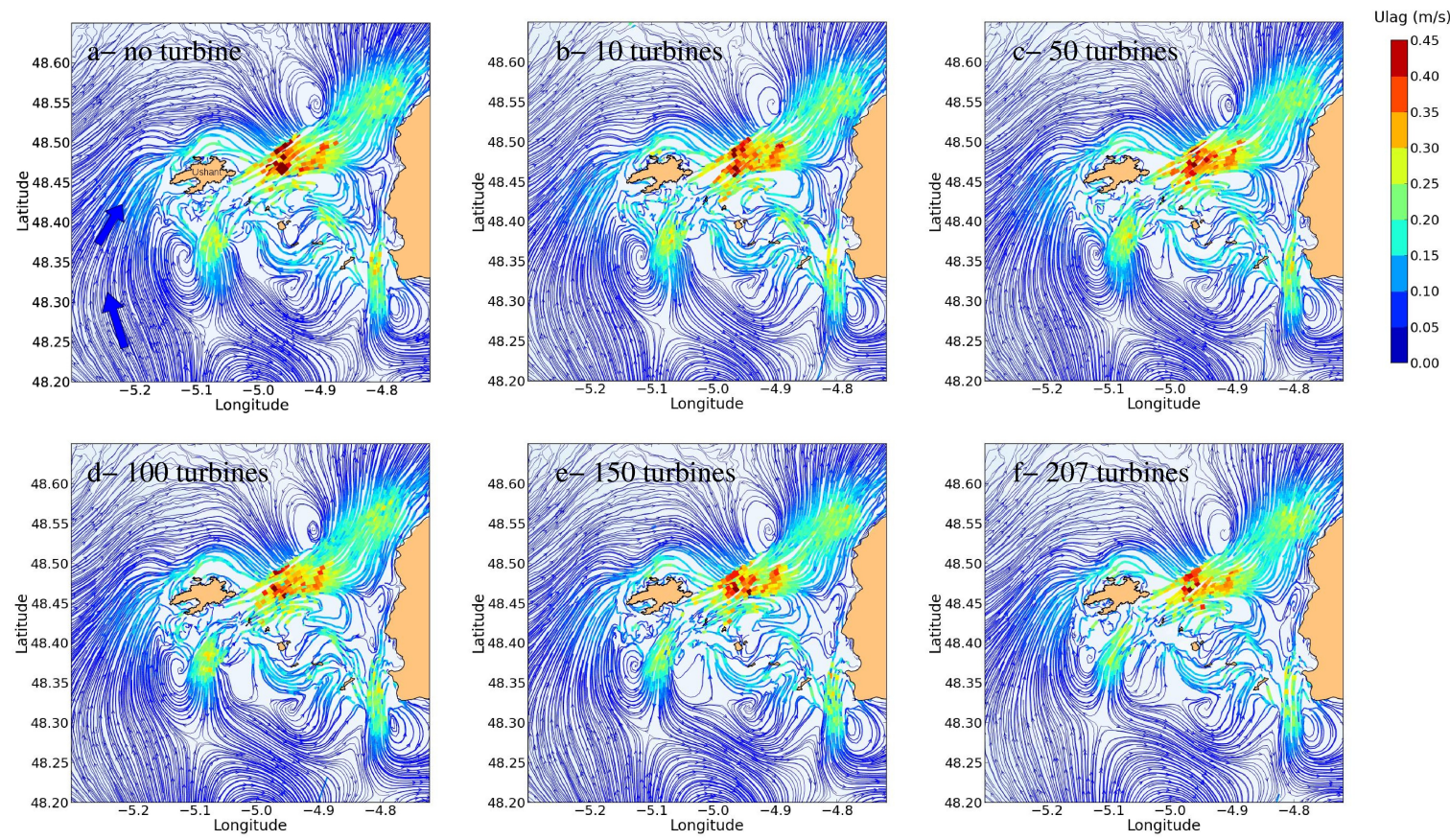

Figure 13: Streamlines from tidal residual Lagrangian currents without turbines and for different numbers of devices in the tidal farm. Following Fig. 6, the regional northward pathway is outlined with blue arrows in Fig. 13-a. 


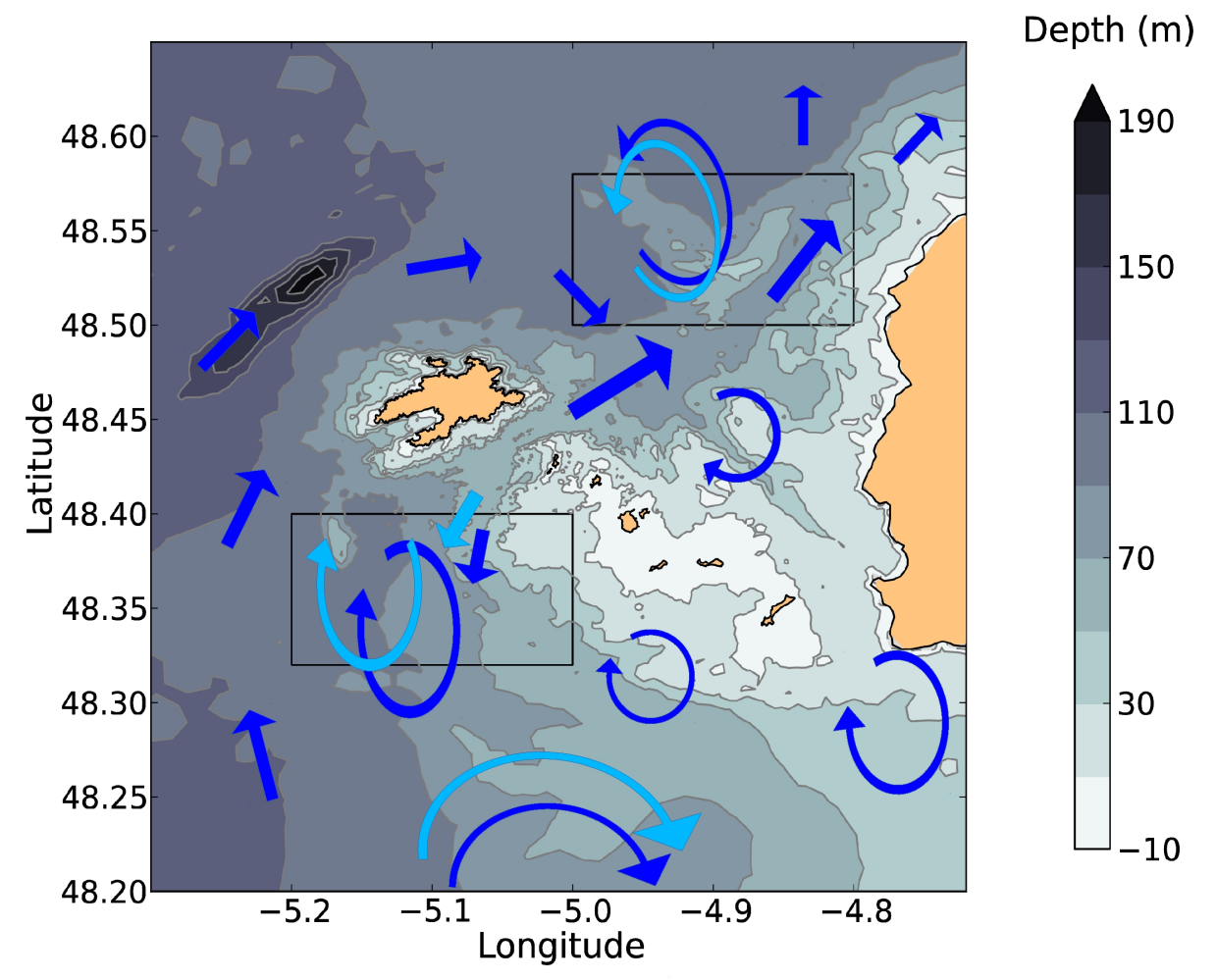

Figure 14: Interpretation of major features of residual Lagrangian currents patterns without (blue lines) and with (light blue lines) a tidal farm of 207 turbines in the Fromveur Strait. Water depth is relative to mean sea level. The black lines delimit the areas displayed in Fig. 15.

sible implications on the evolution of surrounding seabed features, in particular the sand banks of Ushant and the Four. Changes induced by tidal stream power extraction are also more noticeable for the south than the north recirculation. For a configuration with 50 devices, the center of the south eddy moves thus by $820 \mathrm{~m}$ while this displacement is restricted to $220 \mathrm{~m}$ for the north recirculation. The proximity of the south eddy to the Fromveur Strait may explain the greater effects of tidal stream power extraction on this residual pattern. Corroborating the investigation conducted in the previous section, it should finally be noted that the induced modifications do not follow a linear trend for the different configurations implemented. The displacement of eddy centers appears thus to evolve in stages as exhibited by the weak differences between the configurations with 100 and 150 turbines (Fig. 15). 

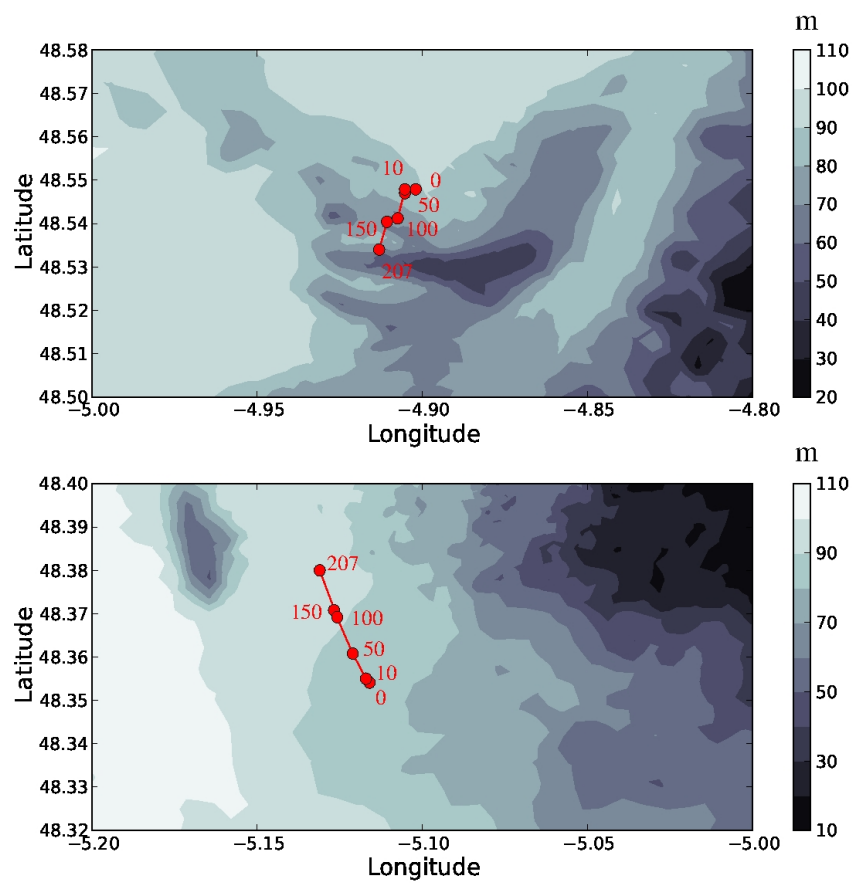

Figure 15: Positions of the centers (red circles) of the northern and southern Lagrangian residual recirculations identified on both part of the Fromveur Strait in the reference configuration and for different numbers of turbines in the tidal farm.

\section{Conclusions}

An original approach, coupling the Lagrangian barycentric method with predictions from a high-resolution depth-averaged circulation model, has been applied to the tidal stream energy site of the Fromveur Strait, in western Brittany, in order to (1) characterise the transport of water particles and (2) assess the effects of tidal stream energy extraction, in idealised $\mathrm{M}_{2}$ and $\mathrm{M}_{4}$ tidal forcings. Numerical predictions have been compared with available in-situ measurements of currents amplitude and direction at two locations: in the Strait and shallow waters of Molène archipelago. The consistency of the predicted tide-induced Lagrangian circulation has furthermore been evaluated with respect to previous investigations conducted at the regional scale of waters bordering western Brittany. Changes induced by a hypothetical tidal farm, varying in devices' number, are investigated with a simplified equivalent drag force term redistributing the sum of turbines' thrust and structural drag forces over the area covered by a proposed array. The main outcomes of the present investigation are as follows:

1. Predicted streamlines refined the characterisation of the tide-induced Lagrangian circulation in the Fromveur Strait with increased spatial resolution in the vicinity of islands and shoals of Ushant-Molène archipe-lago. The computed synoptic view of the Lagrangian circulation identifies, in particular, an accurate position of the cyclonic recirculation in the north of the Strait. Located over the sand bank of the Four, possible correlation may exist between this seabed feature and the Lagrangian residual structure. 
2. A synthetic interpretation of major Lagrangian-circulation patterns is proposed. In the Fromveur Strait, the tide-induced Lagrangian circulation is characterised by a strong asymmetry, between a prominent north-eastern pathway with residual currents up to $0.45 \mathrm{~m} \mathrm{~s}^{-1}$ and a southward circulation. In close correlation with the phase lag between the $\mathrm{M}_{2}$ and $\mathrm{M}_{4}$ harmonic current constituents, this tidal asymmetry results in strong discrepancies of particles trajectories depending on the initial release period during the tidal cycle.

3. Confirming previous investigations, the extraction of tidal stream power results in a nonlinear evolution of the energy produced per device in the Strait. The tide-induced Lagrangian circulation experiences furthermore modifications in amplitude and direction, particularly noticeable along the current stream emerging from the Fromveur Strait. The cyclonic and anti-cyclonic eddies, identified on both part of the Strait, tend, in particular, to get closer to the tidal stream site. Predicted displacements of eddy centers may exceed $1.5 \mathrm{~km}$ for the extreme configuration of the tidal stream farm. Possible implications are expected on the evolution of surrounding sand banks.

The approach retained here, based on the barycentric method, provides thus a synthetic overview of the complex particles trajectories in tide-dominated environments. The derived cartography may, in particular, serve a decision support tool for environmental impact assessment of tidal stream farm. Nevertheless, the present investigation requires further in-situ observations to confirm this synoptic view. Trajectories of drifters, released during tide-dominated periods in Ushant-Molène archipelago, may thus help to refine the assessment of numerical predictions and the particle tracking method retained here. Further three-dimensional numerical studies may furthermore be conducted, at high-spatial resolution in the area of interest, to include (1) a more complex tidal forcing, not only restricted to a single monochromatic wave and (2) the influences of meteorological forcings, in particular the wind-driven circulation. Another prospective will be to include the effects of tidal turbines with more refined approach integrating upstream velocities and wake-wake interactions within the array. The actuator disk theory may thus be implemented integrating the real design parameters of devices in the marine environment, in particular power and thrust coefficients.

\section{Acknowledgements}

The authors are particularly grateful to Jean-Michel Hervouet (EDF R\&D) for his support in applying the particle transport module of TELEMAC 2D. In-situ current measurements were provided by the "Service Hydrographique et Océanographique de la Marine" (SHOM). Simulations were performed with the HPC facilities CAPARMOR ("CAlcul PARallèle Mutualisé pour l'Océanographie et la Recherche") of "Pôle de Calcul Intensif pour la Mer" (PCIM) (http://www.ifremer.fr/pcim). The present paper is a contribution to the LGCE research program DIADEM ${ }^{2}$ ("Design et InterActions des Dispositifs d'extraction d'Energies Marines et le Milieu").

\section{References}

[1] M. Khan, G. Bhuyan, M. Iqbal, J. Quaicoe, Hydrokinetic energy conversion systems and assessment of horizontal and vertical axis turbines for river and tidal applications: a technology status review, Applied Energy 86 (10) (2009) 1823-1835.

[2] S. Neill, M. Hashemi, M. Lewis, The role of tidal asymmetry in characterizing the tidal energy resource of Orkney, Renewable Energy 68 (2014) 337-350. 
[3] M. Lewis, S. Neill, M. Hashemi, M. Reza, Realistic wave conditions and their influence on quantifying the tidal stream energy resource, Applied Energy 136 (2014) 495-508.

[4] P. Evans, A. Mason-Jones, C. Wilson, C. Wooldridge, T. O'Doherty, D. O'Doherty, Constraints on extractable power from energetic tidal straits, Renewable Energy 81 (2015) 707-722.

[5] N. Guillou, G. Chapalain, S. P. Neill, The influence of waves on the tidal kinetic energy resource at a tidal stream energy site, Applied Energy 180 (2016) 402-415.

[6] P. Work, K. Haas, Z. Defne, T. Gay, Tidal stream energy site assessment via three-dimensional model and measurements, Applied Energy 102 (2003) 510-519.

[7] M. Sánchez, R. Carballo, V. Ramos, G. Iglesias, Tidal stream energy impact on the transient and residual flow in an estuary: A 3D analysis, Applied Energy 116 (2014) 167-177.

[8] E. Kirinus, W. Marques, Viability of the application of marine current power generators in the south Brazilian shelf, Applied Energy 155 (2015) 23-34.

[9] N. Guillou, J. Thiébot, The impact of seabed rock roughness on tidal stream power extraction, Energy 112 (2016) $762-773$.

[10] A. Pacheco, Ó. Ferreira, R. Carballo, G. Iglesias, Evaluation of the production of tidal stream energy in an inlet channel by coupling field data and numerical modelling, Energy 71 (2014) 104-117.

[11] J. Thiébot, P. Bailly du Bois, S. Guillou, Numerical modeling of the effect of tidal stream turbines on the hydrodynamics and the sediment transport - Application to the Alderney Race (Raz Blanchard), France, Renewable Energy 75 (2015) 356-365.

[12] L. Ashall, R. Mulligan, B. Law, Variability in suspended sediment concentration in the Minas Basin, Bay of Fundy, and implications for changes due to tidal power extraction, Coastal Engineering 107 (2016) 102-115.

[13] G. I. Shapiro, Effect of tidal stream power generation on the region-wide circulation in a shallow sea, Ocean Sciences 7 (2011) 165-174.

[14] M. Kadiri, R. Ahmadian, B. Bockelmann-Evans, W. Rauen, R. Falconer, A review of the potential water quality impacts of tidal renewable energy systems, Renewable and Sustainable Energy Reviews 16 (2012) 329-341.

[15] K. Edwards, J. Hare, F. Werner, B. Blanton, Lagrangian circulation on the Southeast US Continental Shelf: Implications for larval dispersal and retention, Continental Shelf Research 26 (2006) 1375-1394.

[16] I. Martins, J. Dias, E. Fernandes, J. Muelbert, Numerical modelling of fish eggs dispersion at the Patos Lagoon estuary - Brazil, Journal of Marine Systems 68 (2007) 537-555.

[17] W. Li, H. Tse, L. Fok, Plastic waste in the marine environment: A review of sources, occurence and effects, Science of the Total Environment 566-567 (2016) 333-349.

[18] B. Sanderson, A. Redden, Perspective on the risk that sediment-laden ice poses to in-stream tidal turbines in Minas Passage, Bay of Fundy, International Journal of Marine Energy 10 (2015) 52-69.

[19] J. T. F. Zimmermann, On the Euler-Lagrangian transformation and the Stokes drift in the presence of oscillatory and residual currents, Deep-Sea Research 26 A (1979) 505-520.

[20] R. T. Cheng, V. Casulli, On Lagrangian residual currents with applications in South San Francisco Bay, California, Water Resources Research 18 (6) (1982) 1652-1662.

[21] J. C. Salomon, P. Guéguéniat, A. Orbi, Y. Baron, A Lagrangian model for long-term tidally induced transport and mixing. Verification by artificial radionuclide concentrations, in: J. Guary, P. Guéguéniat, R. P. (Ed.) (Eds.) Radionuclides: A Tool for Oceanography, Elsevier Applied Science Publishers, London, New York, 1988, pp. 384-394.

[22] A. Orbi, J. C. Salomon, Dynamique de marée dans le Golfe Normand-Breton, Oceanologia Acta 11 (1) (1988) 55-64.

[23] B. Blanke, S. Raynaud, Kinematics of the Pacific Equatorial Undercurrent: a Eulerian and Lagrangian approach from GCM results, Journal of Physical Oceanograpy 27 (1997) 1038-1053.

[24] M. Breton, J. Salomon, A 2D long-term advection-dispersion model for the Channel and southern North Sea. Part A: validation through comparison with artificial radionuclides, Journal of Marine Systems 6 (5-6) (1995) $495-514$.

[25] P. Bailly du Bois, F. Dumas, Fast hydrodynamic model for medium- and long-term dispersion in seawater in the English Channel and southern North Sea, qualitative and quantitative validation by radionuclide tracers, Ocean Modelling 9 (2005) 169-210.

[26] A. S. Iyer, S. J. Couch, G. P. Harrison, A. R. Wallace, Variability and phasing of tidal current energy around the United Kingdom, Renewable Energy 51 (2013) 343-357.

[27] H. Muller, B. Blanke, F. Dumas, F. Lekien, V. Mariette, Estimating the Lagrangian residual circulation in the Iroise Sea, Journal of Marine Systems 78 (2009) S17-S36.

[28] H. Muller, B. Blanke, F. Dumas, V. Mariette, Identification of typical scenarios for the surface Lagrangian residual circulation in the Iroise Sea, Journal of Geophysical Research 115 (2010) C07008.

[29] R. Pingree, L. Maddock, The $\mathrm{M}_{4}$ tide in the English Channel derived from a non-linear numerical model of the $\mathrm{M}_{2}$ tide, Deep-Sea Research 25 (1978) 53-63.

[30] N. Guillou, G. Chapalain, Numerical simulation of tide-induced transport of heterogeneous sediments in the En- 
glish Channel, Continental Shelf Research 30 (2010) 806-819.

[31] J. M. Hervouet, Hydrodynamics of free surface flows, modelling with the finite element method, Cambridge University Press, Cambridge, 2007.

[32] A. K. Rastogi, W. Rodi, Predictions of heat and mass transfer in open channels, Journal of the Hydraulic Division 104 (3) (1978) 397-420.

[33] D. Plew, C. Stevens, Numerical modelling of the effects of turbines on currents in a tidal channel - Tory Channel, New Zealand, Renewable Energy 57 (2013) 269-282.

[34] N. Guillou, Modelling effects of tidal currents on waves at a tidal stream energy site, Renewable Energy - (2017) $1-11$.

[35] G. Egbert, S. Y. Erofeeva, Efficient Inverse Modeling of Barotropic Ocean Tides, Journal of Atmospheric and Oceanic Technology 19 (2002) 183-204.

[36] EDF R\&D, TELEMAC modelling system - TELEMAC-3D software - release 6.2, Tech. rep., EDF (2013).

[37] A. Joly, C. Goeury, J. M. Hervouet, Adding a particle transport module to Telemac-2D with applications to algae blooms and oil spills, Technical report, EDF R\&D (2014).

[38] C. J. Willmott, On the validation of models, Physical Geography 2 (2) (1981) 219-232.

[39] J. C. Salomon, M. Breton, An atlas of long-term currents in the Channel, Oceanologia Acta 16 (5-6) (1993) 439448.

[40] L. Carrère, F. Lyard, M. Cancet, A. Guillou, L. Roblou, FES 2012: A new global tidal model taking advantage of nearly 20 years of altimetry, in: Proceedings of meeting 20 Years of Altimetry, 2012.

[41] B. Sinha, R. D. Pingree, The principal lunar semidiurnal tide and its harmonics: baseline solutions for $\mathrm{M}_{2}$ and $\mathrm{M}_{4}$ constituents on the North-West European Continental Shelf, Continental Shelf Research 1 (11) (1997) 1321-1365

[42] L. Pineau-Guillou, PREVIMER Validation des atlas de composantes harmoniques de hauteurs et courants de marée, Technical Report ODE/DYNECO/PHYSED/2013-03 version 1.0, Ifremer (2013).

[43] N. Pouvreau, Trois cents ans de mesures marégraphiques en France : outils, méthodes et tendances des composantes du niveau de la mer au port de Brest, Ph.D. thesis, Université de La Rochelle (2008).

[44] M. Thiébaut, A. Sentchev, Estimation of Tidal Stream Potential in the Iroise Sea from velocity observations by High Frequency Radars, Energy Procedia 76 (2015) 17-26, European Geosciences Union General Assembly 2015 - Division Energy, Resources and Environment, EGU 2015.

[45] S. P. Neill, J. D. Scourse, The formation of headland/island sandbanks, Continental Shelf Research 29 (2009) 2167-2177.

[46] N. Guillou, G. Chapalain, Effects of waves on the initiation of headland-associated sandbanks, Continental Shelf Research 31 (2011) 1202-1213.

[47] J. Lin, B. Lin, J. Sun, Y. Chen, Numerical model simulation of island-headland induced eddies in a site for tida current energy extraction, Renewable Energy 101 (2017) 204-213.

[48] R. D. Pingree, D. K. Griffiths, Sand transport paths around the British Isles resulting from $\mathrm{M}_{2}$ and $\mathrm{M}_{4}$ tidal interactions, Journal of the Marine Biological Association of the United Kingdom 59 (1979) 497-513.

[49] C. T. Friedrichs, D. G. Aubrey, Non-linear tidal distorsion in shallow well-mixed estuaries: a synthesis, Estuarine, Coastal and Shelf Science 27 (1988) 521-545.

[50] M. Thiébaut, A. Sentchev, Asymmetry of tidal currents off the Western Brittany coast and assessment of tidal energy resource around Ushant Island, Renewable Energy 105 (2017) 735-747.

[51] M. Longuet-Higgins, On the transport mass by time-varying ocean currents, Deep-Sea Research 16 (1969) 431447.

[52] R. Ahmadian, R. Falconer, B. Bockelmann-Evans, Far-field modelling of the hydro-environmental impact of tidal stream turbines, Renewable Energy 38 (1) (2012) 107-116.

[53] S. Neill, J. Jordan, S. Couch, Impact of tidal energy convertor (TEC) arrays on the dynamics of headland sand banks, Renewable Energy 37 (2012) 387-397. 